\title{
Effect of Ipriflavone on Bone Changes Induced by Calcium Restricted, Vitamin D Deficient Diet in Rats
}

\author{
Mutsumi TAKENAKA, Masaki NAKATA, Masahiro TOMITA, \\ Toshitaro NAKAGAWA, Seikichi TSUbOI,* Masaaki FUKASE \\ AND TAKUo FUJITA
}

\author{
Third Division, Department of Medicine and *International Center for \\ Exchanging Medical Researches, Kobe University School of \\ Medicine, Kusunokicho, Kobe 650
}

\begin{abstract}
The preventive effect of impriflavone, 7-isopropoxy-isoflavone, on the development of experimental osteopenia in rats was studied. Male Wistar rats (4 weeks old) on a calcium restricted, vitamin D deficient diet were given a daily oral administration of ipriflavone. The administration of ipriflavone (100 $\mathrm{mg} / \mathrm{kg} \mathrm{BW} /$ day) for 40 days significantly inhibited a decrease in the cortical thickness $(14.0 \pm 1.6$ vs. $17.1 \pm 2.9 \%$, mean $\pm S D, p<0.05)$ and bone calcium content $(62 \pm 4 \mathrm{vs} .67 \pm 2 \mathrm{mg}, \mathrm{p}<0.05)$ in the femora of rats induced by a mild calcium restricted $(0.3 \%)$, vitamin $\mathrm{D}$ deficient diet. This compound did not affect serum calcium levels in this condition. But a dose of $20 \mathrm{mg} / \mathrm{kg} \mathrm{BW} /$ day of ipriflavone was insufficient to inhibit a decrease in bone calcium content. In rats fed on a more severe calcium restricted ( $0.03 \%)$, vitamin $\mathrm{D}$ deficient diet, the administration of impriflavone $(100 \mathrm{mg} / \mathrm{kg} \mathrm{BW} /$ day $)$ did not significantly affect the cortical thickness or calcium content. Intestinal calcium absorption measured by the in situ loop method was not significantly different between rats fed with a severe calcium restricted $(0.03 \%)$, D deficient diet with or without ipriflavone ( 20 or $100 \mathrm{mg} / \mathrm{kg} \mathrm{BW} /$ day) These results demonstrate that the new compound, ipriflavone, partially prevents bone calcium loss induced by a mild calcium restricted $(0.3 \%)$, vitamin $\mathrm{D}$ deficient diet in rats. However, the precise mechanism of action of this compound remains unknown.
\end{abstract}

Ipriflavone, 7-isopropoxy-isoflavone, newly synthesized by Chinon (Budapest) (Fig. 1) is one of the flavonoid compounds which are abunduntly found in some plants, particularly in alfalfa.

The Clinical effect of shortening the duration of anginal attack by this compound was flrst reported by Grubich (1979). Significant reduction of the oxygen consumption

Received June 14, 1985 of the isolated heart of rabbit has become evident (Feuer et al, 1981). This compound has also been shown to reduce renal calcium excretion and to enhance calciumstimulated calcitonin secretion in an estrogen dependent manner in rats (Uemura, personal communication; Yamazaki, personal communication). These effects of this compound on both kidney and calcitonin secretion might be beneficial for bone metabolism in osteopenic states including osteoporosis, and 


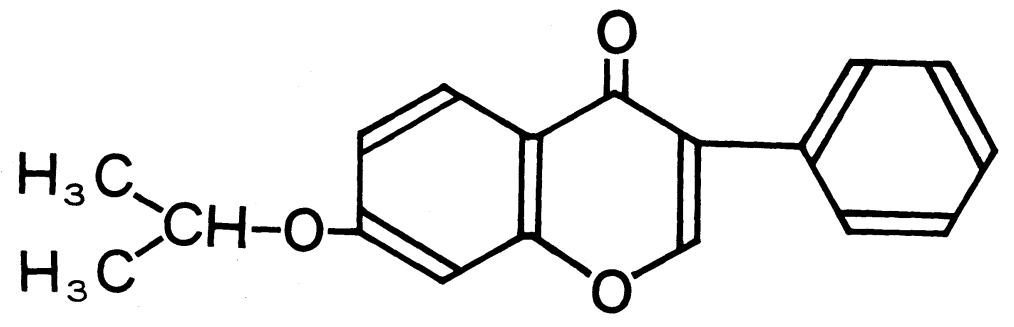

Fig. 1. Structural formula of 7-isoproxy-isoflavone, ipriflavone the effects of this compound on postmenopausal and senile osteoporosis was reported (Takenaka et al., 1982).

We have tested the effect of ipriflavone on bones in rats maintained on a calcium restricted, vitamin D deficient diet. Concentrations of serum calcium and various parameters of bone metabolism, including cortical thickness, ash weight and calcium content were evaluated. Further, the in situ loop method was employed to evaluate the effect of ipriflavone on calcium absorption from gut.

\section{Materials and Methods}

\section{Experiment $A$}

Forty male Wistar rats (4 weeks old) were divided into the following 4 groups and maintained on the following regimen.

I) Normal diet [Ca (1.0\%), vitamin D $200 \mathrm{u}$ / $100 \mathrm{~g}$ diet]

II) Severe calcium restricted $(0.03 \%)$, vitamin $\mathrm{D}$ deficient diet

III) Severe calcium restricted $(0.03 \%)$, vitamin $\mathrm{D}$ deficient diet + ipriflavone $(20 \mathrm{mg} / \mathrm{kg} \mathrm{BW} /$ day $)$

IV) Severe calcium restricted $(0.03 \%)$, vitamin $\mathrm{D}$ deficient diet +ipriflavone $(100 \mathrm{mg} / \mathrm{kg} \mathrm{BW} /$ day $)$

Ipriflavone, mixed into the diet, was given for 50 days to groups III and IV. Group II served as the standard to determine the amount of food intake for pair feeding in this experiment.

On day 50 of the study, rats were killed by bleeding from the abdominal aorta and concentrations of serum calcium were measured. Then the femora were removed and the surrounding soft tissues cleaned away. The cortical thickness was measured by roentogenograms in the anteroposterior position, and expressed as a percentage of the bone width (Hori et al., 1981). After weighing, each bone was defatted with methanolchloroform (1:2 vol/vol) and dried for 6 hours at $120^{\circ} \mathrm{C}$. The ash was weighed after burning for 6 hours at $800^{\circ} \mathrm{C}$ in a furnace (Hori et al., 1981). Calcium content in the bone was determined with an atomic absorption spectrophotometer after treatment with $6 \mathrm{~N} \mathrm{HCl}$.

\section{Experiment $B$}

Forty male Wistar rats (4 weeks old) were divided into 4 groups and maintained on the following regimen for 40 days.

I) Normal diet

II) Mild calcium restricted (0.3\%), vitamin D deficient diet

III) Mild calcium restricted $(0.3 \%)$, vitamin D deficient diet

+ipriflavone $(20 \mathrm{mg} / \mathrm{k} \mathrm{BW} /$ day $)$

IV) Mild calcium restricted (0.3\%), vitamin D deficient diet

+ ipriflavone ( $100 \mathrm{mg} \mathrm{BW} /$ day)

Ipriflavone, mixed into the diet, was given for 40 days. Procedures in this experiment were the same as in Experiment A.

\section{Experiment $C$}

Twenty male Wistar rats (4 weeks old) were divided into 4 groups and maintained on the same diet as in Experiment A for 40 days.

After an overnight fast, rats were anesthetized with sodium pentobarbital intraperitoneally and an in situ loop from the small intestine distal to the pylorus was prepared with two ligations $8 \mathrm{~cm}$ apart. Immediately thereafter, $1.0 \mathrm{ml}$ of a solution containing $0.8 \% \mathrm{NaCl}, 10 \mathrm{mM} \mathrm{CaCl}$ and $0.5 \mu \mathrm{Ci}$ ${ }^{45} \mathrm{Ca}$ was added into this loop (Fujita et al., 1977; Winter et al., 1970 ; Zornitzer and Bronner, 1971). After allowing $60 \mathrm{~min}$, each loop was removed and the luminal content was rinsed out twice with physiologic saline into a centrifuge tube and 
the ${ }^{45} \mathrm{Ca}$ radioactivity was measured. The percent $\mathrm{Ca}$ absorption was calculated according to the following formula.

Total ${ }^{45} \mathrm{Ca}$ administered-Luminal ${ }^{45} \mathrm{Ca}$ Total ${ }^{45} \mathrm{Ca}$ administered

\section{Results}

\section{Experiment $A$}

As shown in Table I, a severe calcium restricted $(0.03 \%)$, vitamin $\mathrm{D}$ deficient diet caused a significant drop in serum calcium levels from $9.3 \pm 0.4$ (mean $\pm S D$ ) to $4.1 \pm$ $0.3 \mathrm{mg} / \mathrm{dl}(\mathrm{p}<0.01)$, ash weight from $275 \pm$ 41 to $119 \pm 6 \mathrm{mg}(\mathrm{p}<0.01)$, bone calcium content per whole bone from $106 \pm 16$ to $44 \pm 3 \mathrm{mg} /$ whole bone $(\mathrm{p}<0.01)$, and cortical thickness from $25.5 \pm 2.3$ to $17.5 \pm 1.7 \%$ (p $<0.01)$, as compared to the normal diet. However, ipriflavone at a dose of either 20 $\mathrm{mg}$ or $100 \mathrm{mg} / \mathrm{kg} \mathrm{BW} /$ day failed to prevent the decrease in any of the parameters mentioned above.

\section{Experiment $B$}

Compared to the normal diet, a mild calcium restricted $(0.3 \%)$, vitamin $\mathrm{D}$ deficient diet caused a significant drop in serum calcium levels from $9.4 \pm 0.4$ to $5.3 \pm 0.5$ $\mathrm{mg} / \mathrm{dl} \quad(\mathrm{p}<0.01)$, ash weight from $428 \pm 24$ to $164 \pm 7 \mathrm{mg} \quad(\mathrm{p}<0.01)$, bone calcium

Table I. Effect of ipriflavone on rat fed a severe calcium restricted, vitamin D deficient diet (Experiment A).

\begin{tabular}{|c|c|c|c|c|c|}
\hline & & $\begin{array}{l}\text { Serum Ca } \\
\text { (mg) }\end{array}$ & $\begin{array}{c}\text { Cortical thickness } \\
(\%)\end{array}$ & $\begin{array}{l}\text { Ash weight } \\
\text { (mg) }\end{array}$ & $\begin{array}{c}\text { Ca. content } \\
\text { (mg/whole bone) }\end{array}$ \\
\hline I) & Normal & $9.3 \pm 0.4$ & $25.5 \pm 2.3$ & $275 \pm 41$ & $106 \pm 16$ \\
\hline II) & $\mathrm{Ca}(0.03 \%) \mathrm{D}(-)$ & $4.1 \pm 0.4^{*}$ & $17.5 \pm 1.7^{*}$ & $119 \pm 6^{*}$ & $44 \pm 3^{*}$ \\
\hline III) & $\begin{array}{l}\text { Ca }(0.03 \%) \text { D (-) } \\
\text { +ipriflavone } \\
(20 \mathrm{mg} / \mathrm{kg})\end{array}$ & $4.2 \pm 0.4$ & $16.6 \pm 3.1$ & $115 \pm 6$ & $43 \pm 3$ \\
\hline IV) & $\begin{array}{l}\text { Ca }(0.03 \%) \text { D }(-) \\
+ \text { ipriflavone } \\
(100 \mathrm{mg} / \mathrm{mg})\end{array}$ & $4.1 \pm 0.4$ & $17.4 \pm 1.6$ & $122 \pm 12$ & $43 \pm 5$ \\
\hline
\end{tabular}

Table II. Effect of ipriflavone on rat fed a mild calcium restricted, vitamin D deficient, diet (Experiment B).

\begin{tabular}{|c|c|c|c|c|c|}
\hline & & $\begin{array}{l}\text { Serum } \mathrm{Ca} \\
(\mathrm{mg})\end{array}$ & $\begin{array}{c}\text { Cortical thickness } \\
(\%)\end{array}$ & $\begin{array}{l}\text { Ash weight } \\
\text { (mg) }\end{array}$ & $\begin{array}{c}\text { Ca. content } \\
\text { (mg/whole bone) }\end{array}$ \\
\hline I) & Normal & $9.4 \pm 0.4$ & $29.2 \pm 0.7$ & $428 \pm 24$ & $167 \pm 1$ \\
\hline II) & $\mathrm{Ca}(0.3 \%) \mathrm{D}(-)$ & $5.3 \pm 0.5^{*}$ & $14.0 \pm 1.6^{*}$ & $164 \pm 7^{*}$ & $62 \pm 4^{*}$ \\
\hline III) & $\begin{array}{l}\text { Ca }(0.3 \%) \mathrm{D}(-) \\
+ \text { ipriflavone } \\
\quad(20 \mathrm{mg} / \mathrm{kg})\end{array}$ & $5.4 \pm 0.6$ & $17.2 \pm 3.3^{* *}$ & $161 \pm 15$ & $61 \pm 5$ \\
\hline \multirow[t]{2}{*}{ IV) } & $\begin{array}{l}\text { Ca }(0.3 \%) \text { D }(-) \\
+ \text { ipriflavone } \\
(100 \mathrm{mg} / \mathrm{kg})\end{array}$ & $5.7 \pm 0.4$ & $17.1 \pm 2.9^{* *}$ & $175 \pm 5^{* *}$ & $67 \pm 2 * *$ \\
\hline & & & (1) & $\begin{aligned} * & : \mathrm{p}<0 . \\
* * & : \mathrm{p}<0 .\end{aligned}$ & $\begin{array}{l}.01 \text { (vs. group I) } \\
.05 \text { (vs. group II) }\end{array}$ \\
\hline
\end{tabular}


content per whole bone from $167 \pm 1$ to $62 \pm 4 \mathrm{mg}(\mathrm{p}<0.01)$ and cortical thickness from $29.2 \pm 0.7$ to $14.0 \pm 1.6 \% \quad(p<$ 0.01). The administration of $100 \mathrm{mg} / \mathrm{kg} \mathrm{BW}$ /day of ipriflavone did not inhibit a drop in serum calcium levels, but significantly inhibited a decrease in ash weight $(175 \pm 5 \mathrm{vs}$. $164 \pm 7 \mathrm{mg} /$ whole bone, $\mathrm{p}<0.05)$, bone calcium content $(67 \pm 2$ vs. $62 \pm 4 \mathrm{mg} /$ whole bone, $\mathrm{p}<0.05)$ and cortical thickness (17.1 \pm 2.9 vs. $14.0 \pm 1.6 \%, \mathrm{p}<0.05)$. The administration of $20 \mathrm{mg} / \mathrm{kg} \mathrm{BW} /$ day of ipriflavone significantly inhibited a decrease in cortical thickness $(17.2 \pm 3.3$ vs. $14.0 \pm 1.6 \%, \quad \mathrm{p}<$ $0.05)$, but did not alter bone calciumc ontent per whole bone or ash weight. (Table II)

\section{Experiment $C$}

Duodenal calcium absorption in the in situ loop methood was low in the severe calcium restricted, vitamin $\mathrm{D}$ deficient diet group $(31.0 \pm 5.4 \%)$ compard to that in animals given the normal diet $(65.7 \pm 9.1 \%)$. Duodenal calcium absorption in the groups given ipriflavone $(20 \mathrm{mg}$ or $100 \mathrm{mg} / \mathrm{kg} \mathrm{BW} /$ day) was not different from that in controls without ipriflavone. (Table III)

Table III. Ca absorption from duodenal loop in situ (experiment $\mathrm{C}$ )

\begin{tabular}{ccc}
\hline \hline & $\%$ absorption \\
\hline I) & Normal & $65.7 \pm 9.1$ \\
II) & $\mathrm{Ca}(0.03 \%), \mathrm{D}(-)$ & $31.0 \pm 5.4$ \\
III) & $\mathrm{Ca}(0.03 \%), \mathrm{D}(-)$ & $30.4 \pm 6.0$ \\
& + Ipriflavone \\
& $(20 \mathrm{mg} / \mathrm{kg})$ \\
IV) & $\begin{array}{l}\text { Ca }(0.03 \%), \mathrm{D}(-) \\
+\end{array}$ & $34.3 \pm 4.0$ \\
& $\begin{array}{l}\text { Ipriflavone } \\
(100 \mathrm{mg} / \mathrm{kg})\end{array}$ \\
\hline
\end{tabular}

\section{Discussion}

In the present study we demonstrated that the calcium restricted, vitamin D deficient diet caused not only a sharp drop in serum calcium levels, but a decrease in ash weight, calcium content per whole bone and cortical thickness of the femora. The administration of ipriflavone $(100 \mathrm{mg} / \mathrm{kg}$ $\mathrm{BW} /$ day for 40 days) significantly in hibited a decrease in bone calcium content and cortical thickness of the femora of rats maintained on the mild calcium restricted $(0.3 \%)$, vitamin $\mathrm{D}$ deficient diet. But a dose of $20 \mathrm{mg} / \mathrm{kg} \mathrm{BW} /$ day was insufficient to inhibit a decrease in bone calcium content (Table II). In rats maintained on the severe calcium restricted $(0.03 \%)$, vitamin $\mathrm{D}$ deficient diet, the effect of this compound on bone was less remarkable and a decrease in bone calcium content was not prevented significantly by either $20 \mathrm{mg} / \mathrm{kg} \mathrm{BW} /$ day or $100 \mathrm{mg} / \mathrm{kg} \mathrm{BW} /$ day of ipriflavone (Table I).

Since it has been reported that an increase in the bone marrow cavity over the thickness of the bone was correlated with the degree of bone resorption in growing rats (Baylink et al., 1970; klein, 1980), our data suggest that the administration of ipriflavone to rats on mild calcium restricted, vitamin $\mathrm{D}$ deficient diet resulted in inhibition of bone resorption. One likely explanation of the relative ineffectiveness of this compound in severe calcium restricted, vitamin $\mathrm{D}$ deficient rats might be a rather weak action of this compound to prevent and overcome a profound change in bone resorption in this condition.

Whether ipriflavone stimulated bone formation in our rachitic animal model or not is difficult to determine. However, it seems less likely that ipriflavone increases calcium content of bone by stimulating bone for-mation (mineralization) because it did not affect serum calcium levels and a major cause of insufficient mineralization in the rachitic state is hypocalcemia (Howard and Baylink, 1980). The possibility that ipriflavone plays a role in the maturation of collagen and in the growth and development of endochondral cartilage cannot be ruled out. 
As for a possible role of the gut, the effect of ipriflavone on intestinal calcium absorption is unlikely, since intestinal absorption in the severe calcium restricted, vitamin $\mathrm{D}$ deficient rats was not apparently influenced by this compound (Table III). However, since our experiment was carried out only in the animals on the severe calcium restricted $(0.03 \%)$, vitamin D deficient diet and not performed in rats fed on the mild calcium restricted, vitamin D deficient diet, the true contribution of the change in calcium absorption induced by ipriflavone might not be ruled out completely.

Urinary calcium excretion in both ipriflavone-treated and control rats on either a mild or a severe calcium restricted diet was so low (less than $0.3 \mathrm{mg} / \mathrm{day}$, data not shown) that a direct effect of ipriflavone on the change of calcium handling in the kidneys was not evaluated. Renal adaptation to calcium restriction (Armbrecht et al., 1981) is most likely to be responsible for low urinary calcium excretion.

Taken together, we report here that a new compound, ipriflavone, partially prevents bone calcium loss in mild calcium restricted $(0.3 \%)$, vitamin $\mathrm{D}$ deficient rats. Whether this effect of ipriflavone is a direct effect on bone or not remains to be elucidated. Also, although not apparent in our study, a possible effect of ipriflavone on intestinal and/ or renal calcium handling in other experiment conditions should be investigated further.

\section{References}

Armbrecht, H. J., C. J. Gross and T. V. Zenser (1981). Effect of dietary calcium and phosphorus restriction on calcium and phosphorus balance in young and old rat. Arch. Biochem. Biophys. 210, 179-185.

Baylink, D. J., M. Stauffer, J. Wergedal and C. Rich (1970). Formation, mineralization, and resorption of bone in vitamin D-deficient rats. J. Clin. Invest. 49, 1122-1134.

Feuer, L., P. Barath, I. Strauss and E. Kekes (1982). Experimental studies on the cardiological effects of ipriflavone on the isolated rabbit heart and in rat and dog. ArtneimForsch. 31, 953-958.

Fujita, T., M. Ohata, K. Okano and M. Yoshikawa (1977). Endocrine control of intestinal calcium excretion. Endocrinol. Japon. 24, 15-18.

Grubich, V. (1979). Cardiovascular properties of 7-isopropoxyisoflavone. Lancet. 1, 15-18.

Howard, G. A. and D. J. Baylink (1980). Matrix formation and osteoid maturation in vitamin D-deficient rats made normocalcemic by dietary means. Mineral and Electrolyte Metabolism. 3, 44-50.

Hori, M., Y. Tsukamoto, K. Sugimoto, T. Sakurada, S. Watanabe, K. Hayano and H. Orimo (1981). Effect of elcatonin on the development of experimental osteoporosis in rats. Bone Metabolism. 14, 228-233. (in Japanese)

Klein, L. (1980). Direct measurement of bone resorption and calcium conservation during vitamin D deficiency or hypervitaminosis D. Proc. Natl. Acad. Scien. USA. 77, 1818-1822.

Takenaka, M., H. Baba, K. Sakaguchi, Y. Imai, T. Fukami, M. Tsutsumi, Y. Yoshimoto and T. Fujita (1982). Effect of ipriflavone on osteoporosis. Bone Metabolism. 15 Supple, 58. (Abstract) (in Japanese)

Winter, M., Morava, G. Simon and J. Sos (1970). The role of the parathyroid glands in the absorption of calcium from the small intestine. J. Endocr. 27, 65-72.

Zornitzer, A. and F. Bronner (1971). In situ studies of calcium absorption in rats. Am. J. Physiol. 220, 1261-1266. 